\title{
ETPF Regimen
}

National Cancer Institute

\section{Source}

National Cancer Institute. ETPF Regimen. NCI Thesaurus. Code C161954.

A chemotherapy regimen consisting of cetuximab, docetaxel, cisplatin, and 5-fluorouracil for the treatment of squamous cell carcinoma of the oropharynx. 